\title{
Articulação sonora e visual em performances intermédia site-specific
}

\author{
Frederico Dinis \\ Centro de Estudos Interdisciplinares do Século XX (CEIS20), \\ Universidade de Coimbra, Portugal
}

\begin{abstract}
Aiming to explore the diverse nature of sound and image, thereby establishing a bridge with the symbiotic creation of sensations and emotions, this paper aims to present the development and construction of a proposal for the creation of site-specific performances, based on sound and visual articulation and intermedia practices.

Using as focal points several places, the authors try to look beyond time and develop site-specific intermedia performances, attempting to understand the past and sketching new configurations for the (re)presentation of these places identity, guiding the audience through a journey of perceptual experiences, using ambient electronic music, soundscapes and videos.

This presentation also aims to present a practice-as-research project, which had as its starting point the apprehension of memories and the history of these places, emphasizing concepts such as local context, site-specific, sense of place and identity.

For this, the authors present the development of some experimental approaches and critical forms of expression and communication that relate or incorporate sound and visual mediums. They also bring forward some concerns about the aesthetic experience and communicative functionality, and how the relationship between art and technology has an effect on artistic culture and new contemporary sitespecific intermedia performances.
\end{abstract}

Keywords: Performance, Intermedia, Identity, Site-specific, Sense of place

\section{Introdução}

Um dos formatos que desde sempre se destacou por quebrar as regras dos movimentos artísticos vigentes foi a performance.

Neste contexto, graças à apropriação tecnológica e à expansão a outros media, a performance intermédia ganhou destaque entre as práticas criativas, já que permitiu a descentralização do corpo e do performer, abrindo-se a outros media como o som ou a imagem.

$O$ conceito de performance pode ser entendido através de diferentes perceções, que resultam de distintas abordagens disciplinares, áreas artísticas ou contextos culturais.

É devido a algum desentendimento e coerência do conceito que a performance apresenta um grande potencial investigativo e exploratório partindo inclusive das suas diferentes conceções, proporcionando assim leituras pessoais sobre a confluência entre o visual e o sonoro como tema de reconhecimento criativo.

Nomeadamente explorando o diálogo entre o som e a imagem de forma a desenvolver narrativas que permitam que o espectador tenha cada vez mais uma imersão contemplativa, num ambiente sensorial.

Como ponto de partida para o desenvolvimento destas narrativas sonoras e visuais tem-se um conjunto de práticas artísticas associadas à música eletrónica ambiental, que assentam muito mais em texturas atmosféricas do que em variações rítmicas, e apontam-se percursos, nos movimentos artísticos associados à arte da performance, que contextualizam as performances intermédia contemporâneas que envolvem estéticas alternativas e são tecnologicamente inovadoras.

\section{A Música Eletrónica Ambiental}

Importa primeiramente apresentar uma breve explanação do historial da música eletrónica ambiental, revendo e desconstruindo conceções associadas ao desenvolvimento deste estilo musical enquadrado na música eletrónica desde a sua vanguarda, no final do séc. XIX e início do séc. XX.

\section{A Vanguarda}

Podem ser apontadas como sendo a origem da música eletrónica, em geral, e da música eletrónica ambiental, em particular, as primeiras composições musicais e experimentações sonoras realizadas por Érik Satie (França, 1866-1925), Arnold Schoenberg (Áustria, 1874-1951) e Luigi Russolo (Itália, 18851947), devido à influência que estes criadores tiveram no trabalho desenvolvido por outros autores em anos subsequentes.

O trabalho de composição desenvolvido por Érik Satie é caracterizado por ter um caráter suave e um encanto que resulta da sua honestidade sonora e, principalmente, por não ser fiel a qualquer estética musical muito vincada.

Outro autor fundamental na compreensão das alterações operadas na composição musical e que motivaram as primeiras experimentações eletrónicas foi Arnold Schoenberg. Schoenberg baseou o seu trabalho na dissolução da tonalidade na música, fazendo desta característica das suas composições um passo lógico e inevitável na evolução da música ocidental, rompendo com as fronteiras instituídas.

Se a quebras das regras vigentes para a construção das primeiras composições musicais de Satie e de Schoenberg foram fundamentais para a génese das primeiras experimentações de música eletrónica, já as experiências sonoras de Luigi Russolo foram decisivas para a sua prática experimental.

Russolo, considerado por muitos como sendo o primeiro artista de noise music, no seu manifesto, L'Arte dei Rumori (traduzido para The Art of Noise), defende que "a revolução industrial deu aos homens modernos uma maior capacidade de apreciar sons 
mais complexos" (Luigi Russolo, 1967), enfatizando que o tradicional confinamento da música à melodia seria substituído no futuro pela noise music (Chilvers e Glaves-Smith, 2009).

Tal como refere Hegarty (2007), embora as obras de Russolo tenham pouca semelhança com a noise music contemporânea, as suas criações pioneiras não podem ser ignoradas como tendo sido etapas fundamentais quer para a evolução de vários géneros musicais, nomeadamente a música eletrónica de cariz mais experimental.

\section{As Primeiras Experimentações}

Se a música avant-garde surge como a forma de enquadrar quem procura romper limites instituídos, mas trabalhando dentro das estruturas musicais tradicionais, as primeiras experimentações associadas à música eletrónica surgem para desafiar a ideia de que poderiam ser consideradas como sendo música, promovendo assim a vanguarda do experimentalismo sonoro.

Nesta procura incessante para quebrar regras e experimentar novos caminhos destaca-se o trabalho desenvolvido por Edgard Varèse (França, 18831965), Pierre Schaeffer (França, 1910-1995), John Cage (EUA, 1912-1992) e Karlheinz Stockhausen (Alemanha, 1950-1990), trabalhos estes de extrema importância no desenvolvimento posterior de toda a música electrónica.

Tal como aponta Russcol (1972) Schaeffer, ao ter como ponto de partida objetos sonoros equivalentes a imagens visuais, altera completamente os procedimentos da composição musical e faz com que a experiência da música concreta consista na construção desses objetos sonoros, não com o recurso a números e segundos do metrónomo, mas sim com pedaços de tempo arrancados do cosmos.

Desafiando sempre o conceito do que é música, John Cage permaneceu na vanguarda do experimentalismo durante a maior parte de sua carreira, colaborando e influenciando gerações de compositores, escritores, dançarinos e artistas visuais.

Foi graças ao trabalho desenvolvido por Stockhausen, Varèse, Schaeffer e Cage, e à sua procura incessante de novas experimentações sonoras que se abriram outras alternativas para o aparecimento da música eletrónica como a conhecemos hoje.

\section{As Fundações da Música Eletrónica}

As fundações da música eletrónica contemporânea têm por base o trabalho desenvolvido por três projetos que revolucionaram a forma como a música eletrónica passou a ser vista e assim influenciaram a quase totalidade dos projetos associados aos diversos estilos deste género. Falamos do trabalho desenvolvido pelos Tangerine Dream, Kraftwerk e Yellow Magic Orchestra.

Promotores Alemães de um estilo de música electrónica muito imaginativa, os Tangerine Dream foram pioneiros na nova era da música eletrónica de cariz mais atmosférica.

Se os Tangerine Dream inovaram musicalmente com as suas paisagens sonoras associadas ao advento da era espacial já os Kraftwerk tornaram-se na maior influência da música eletrónica produzida nas décadas de 80 e 90 graças à sua sonoridade minimalista e totalmente eletrónica.

A assinatura sonora dos Kraftwerk combina frequências e ritmos repetitivos com melodias cativantes, que seguem um estilo clássico de harmonia, com o auxílio de equipamentos minimalistas e eletrónicos. O som característico do Kraftwerk foi revolucionário e teve um efeito duradouro em muitos géneros de música moderna, popularizando a música eletrónica.

Se na Alemanha os Tangerine Dream e os Kraftwerk revolucionaram a música eletrónica, no Japão foram os Yellow Magic Orchestra (YMO) que quebraram as regras com a sua sonoridade techno-pop.

Com o uso precursor de sintetizadores, sequenciadores e baterias eletrónicas os YMO, de Ryuichi Sakamoto, continuam hoje em dia a ser uma influência seminal na música eletrónica contemporânea.

Seja através das paisagens sonoras atmosféricas e espaciais, dos Tangerine Dream, ou pelas sonoridades hipnóticas minimais e robotizadas electronicamente, dos Kraftwerk, ou pelos sons samplados, sequenciados sintetizados dos YMO a música eletrónica como a conhecemos atualmente nunca seria a mesma sem a inovação presente nos trabalhos destes três projetos.

\section{A Génese da Música Eletrónica Ambiental}

Se os Kraftwerk são a maior influência associada à música eletrónica em geral, já a génese da música eletrónica ambiental surge associada ao lançamento, em 1978, do álbum Ambient 1: Music for Airports de Brian Eno.

Ambient 1: Music for Airports foi desenvolvido para ser tocado num local cultural ou num espaço público. "Os aeroportos, como ponto de partida modernos, são lugares onde ocorrem reuniões ou começam separações, conforme as pessoas chegam ou partem. São também locais de comércio, de anúncios estridentes, de tédio e de tensão, e Eno teve tudo isto em consideração criando uma obra que tranquiliza as pessoas, que transmite um espírito de esperança e que acalma a ansiedade das chegadas ou das partidas" (Buck, 2008).

Tal como Cage anteriormente, Eno joga neste trabalho com envolventes da consciência dos ouvintes, não só aumentando o tempo de cada uma das peças sonoras, mas também estendendo o comprimento entre as seções que as compõem para um nível exagerado. Ao não se saber quando as peças param ou começam, os ouvintes envolvem-se ainda mais na imersividade do som.

Ambient 1: Music for Airports foi um passo em frente no desenvolvimento da música contemporânea que tem como única base a textura, tratando-se de um trabalho sobre escutar e sobre como ouvir. Se o recurso à melodia, ao ritmo, à harmonia ou à letra ficou pelo caminho na construção deste trabalho e, principalmente, no desenvolvimento deste género musical, então é porque não seria necessário. 


\section{A Massificação da Música Eletrónica Ambiental}

A música eletrónica ambiental produzida na primeira década dos anos 2000 incorporou pouca inovação, após o seu grande crescimento durante as duas décadas anteriores, exceção feita aos trabalhos desenvolvidos por Murcof e Alva Noto e Vladislav Delay.

Os trabalhos de Murcof combinam a orquestração minimalista contemporânea com techno melancólico, de forma a criar ambientes sonoros perto do devocional. Tratam-se assim de trabalhos com sonoridades misteriosas e atmosféricas que remetem o ouvinte para paisagens estéreis e lunares, impulsionando os modelos da eletrónica ambiental para novas experimentações contemplativas.

Dentro de uma corrente mais IDM e ambiental experimental Alva Noto apresenta colagens sonoras sem títulos, construídas a partir do som real de ruídos elétricos e cliques, amplificados e organizados numa série de movimentos discretos, que se movem além da mera música eletrónica ambiental para um novo domínio experimental.

Destaca-se ainda o trabalho do produtor Vladislav Delay, cujo estilo combina distorções, silenciadores analógicos e ruídos, criando composições austeras e minimalistas, que enfatizam as linhas de baixo e de percussão, e o uso intenso de efeitos sonoros.

Estas três abordagens, apesar de semanticamente enquadradas na música eletrónica ambiental, demonstram já uma grande diversidade criativa na procura de novas sonoridades e deram origem a uma prática artística que influenciou fortemente os anos seguintes.

\section{Novos Caminhos para a Música Eletrónica Ambiental}

A partir da segunda década dos anos 2000 dá-se uma nova expansão da música eletrónica ambiental e da IDM com a aparição de novos projetos, do qual se destacam Forest Swords, Old Apparatus e The Haxan Cloak, projetos estes que representam novos caminhos para outras sonoridades que intersectam a música eletrónica ambiental.

No trabalho de estreia de Forest Swords (aka Matthew Barnes), fica demonstrado que se trata de uma odisseia mergulhada num tentador misticismo de sonoridades quase desconhecidas onde Barnes faz um incrivel trabalho de envolvimento dos ouvintes nas suas texturas cacofónicas, que são o tecido da sua realidade sonora.

Já a mistura perfeita entre texturas sonoras não naturais, melodias orgânicas e vocalizações arrastadas do trabalho de estreia do coletivo Old Apparatus desenrola-se como um sonho profundo assombrado, soando a música construída num qualquer bunker subterrâneo, escondido longe do mundo, onde a matéria prima original são apenas lembranças vagas.

Por ultimo, o trabalho de estreia de The Haxan Cloak aproveita ao máximo a duração dos temas desenvolvendo assim uma verdadeira narrativa, onde a criação sonora se constrói recorrendo a espaços negativos, a composições labirínticas e a melodias baseadas em sintetizadores, que explodem da tranquilidade para o caos.

Em suma, verifica-se que, apesar da massificação da música eletrónica ambiental, a procura de novas sonoridades tem sido constante e tem impulsionado novas correntes que procuram um mesmo objetivo: envolver os ouvintes em ambientes percetuais, que os transportem para lugares nunca imaginados.

\section{A Performance Multimédia}

Procuraremos identificar e discutir o percurso dos movimentos artísticos associados à arte da performance, contextualizando as performances multimédia contemporâneas na história e nas linguagens dominantes na arte da performance, desde o futurismo e a vanguarda, no final do séc. $X I X$ e início do séc. $X X$, até às novas abordagens na reconstrução visual do fenómeno sonoro, abordagens estas que influenciam indubitavelmente o trabalho atual do autor.

De forma a balizar o nosso trabalho assumimos o conceito de multimédia como sendo a combinação de meios ou de tipos de média, tal como proposto por Packer e Jordan (2001).

Ao longo do trabalho procuraremos questionar e discernir o que é verdadeiramente novo na ontologia dos novos media e a sua aplicação no âmbito da performance multimédia.

\section{Uma Genealogia da Performance Multimédia}

O teatro, a dança e a arte da performance sempre foram formas interdisciplinares ou multimédia e as raízes das práticas da performance multimédia podem ser rastreadas através de décadas, ou até mesmo séculos da história da performance.

Na viragem do milénio foram publicadas um vasto número de antologias reunindo textos historicamente importantes e que previram ou influenciaram a teoria e a prática associada aos novos media. Nestas publicações incluem-se: Multimedia: From Wagner to Virtual Reality (2001) de Randall Packer e Ken Jordon, The New Media Book (2002) de Dan Harries, Prefiguring Cyberculture: An Intellectual History (2002) de Darren Tofts, Annemarie Jonson e Alessio Cavallaro, e The New Media Reader (2003) de Noah Wardrip-Fruin e Nick Monfort. Estes últimos justapõem textos de pioneiros da tecnologia e teóricos dos media com textos de artistas, traçando assim paralelos históricos entre os seus pensamentos e obras.

Além da importância destas antologias é também importante analisarmos o contributo de Richard Wagner e a sua noção de Gesamtkunstwerk, ou seja, obra de arte total, apresentada no seu trabalho The Artwork of the Future (1849), e cuja visão resultava na unificação criativa de várias formas de arte, nomeadamente o teatro, a música, o canto, a dança, a poesia dramática, o design, a luz e as artes visuais.

Procuramos assim não só identificar a genealogia 
da performance multimédia, partindo das referências apresentadas, mas também discutir as suas derivações de forma a rever e desconstruir esta forma de performance.

A performance multimédia deve ser analisada como uma extensão de uma história contínua da adoção e adaptação de tecnologias para aumentar o efeito estético da performance e das artes visuais e a sensação de espetáculo, o seu impacto emocional e sensorial, o seu jogo de significados e associações simbólicas e o seu poder intelectual.

\section{O Futurismo e a Vanguarda do Início do Séc. $X X$}

Ao longo da edificação desta arqueologia argumentamos que podem ser estabelecidos paralelos claros entre os movimentos de vanguarda do século $\mathrm{XX}$, como o futurismo, com a era digital dos anos 90, já que tal como defendido por Rutsky (1999) ambos surgiram em épocas de revolução tecnológica comparáveis.

Tanto o futurismo como as tecnologias digitais apresentaram-se inicialmente como filosofias de vida. Mais tarde compreendeu-se que se tratavam de desenvolvimentos técnicos que rapidamente se tornaram ultrapassados, exigindo assim um maior esforço para evitar que ficassem barricadas nas suas próprias dificuldades técnicas, limitações e clichês (Dixon, 2007).

Pretendemos assim analisar $o$ legado da vanguarda do início do século $\mathrm{XX}$, ligando a performance multimédia de hoje com as teorias e práticas do futurismo, construtivismo, dadaísmo, surrealismo e expressionismo.

Assim, demonstraremos a centralidade absoluta da estética e filosofia futuristas na performance atual e argumentaremos que o legado do futurismo à arte dos novos media, em geral, e para a performance multimédia, em particular, tem sido muito subestimado.

$\mathrm{Se}$ ○ futurismo forma uma base conceptual e filosófica para a performance multimédia contemporânea e o construtivismo fornece o modelo matemático e metodologia formal, argumentamos que os restantes movimentos da vanguarda na Europa fornecem fontes de inspiração para o seu conteúdo e estilo de expressão artística.

Assim, a performance multimédia explora geralmente representações do subconsciente, sonhos e mundos de fantasia, assim como outros temas centrais à arte, cinema e teatro surrealista do início do séc. XX. As colagens e cutups associadas ao dadaísmo francês e surrealismo movem-se para o reino virtual, com o computador a tornar-se o manipulador da imagem. As estruturas performativas dadaístas são reinventadas agora no plano digital.

$\mathrm{Na}$ sua análise de perspetivas críticas e filosóficas sobre tecnologia Coyne (1999) apresenta detalhadamente como os princípios do surrealismo ressoam com aqueles que expõem o mundo digital, mundo este vertiginoso, cheio de justaposições estranhas, complexidades, níveis de significado e contradições.
Para completar esta análise dos movimentos de vanguarda do início do século XX, defendemos que a ligação do expressionismo à performance multimédia é a menos distinta e refere-se principalmente ao uso da distorção e do exagero nas formas visuais, desde a face e do corpo humano, às vistas cénicas e mundos virtuais.

\section{A Arte ao Vivo e a Arte Expandida}

Após a vanguarda do início do século $X X$, importa interligar e relacionar a arte ao vivo e o conceito de happening com o desenvolvimento da performance multimédia.

Aqui destacamos a visão de John Cage, descrita no seu manifesto O Futuro da Música: Credo (1958), que se baseava na ideia de que onde quer que estejamos, o que ouvimos é basicamente ruído, quer se trate de um camião a $80 \mathrm{~km} / \mathrm{h}$, da chuva ou da estática entre estações de rádio. Cage pretendia apreender e controlar esses sons e usá-los não como efeitos sonoros, mas como instrumentos musicais, retomando o defendido por Russolo (1967) e Cowell (1996).

Importantes foram também as novas abordagens à performance por parte de Allan Kaprow com os seus happenings, eventos ao vivo onde os artistas apresentavam publicamente o que por norma só apresentavam em privado, aumentando assim responsabilidade do observador, já que este se tornava integrante do happening, vivenciando-o simultaneamente (Kaprow, 1966).

Apesar de estes movimentos artísticos não estarem diretamente ligados à performance multimédia, muitos dos trabalhos realizados desenvolveram-se através da combinação de meios ou de tipos de média, expandindo sentidos estéticos que se refletem em muitas linguagens artísticas posteriores.

\section{O Advento dos Novos Media}

Tal como a história política e social, a história da performance envolveu evoluções graduais e incrementais, pontuadas por períodos intensos de mudanças mais bruscas.

Neste trabalho defendemos três períodos de evoluções mais radicais, (i) um associado ao futurismo, em 1910, (ii) outro associada à performance com recurso a diferentes meios, em 1960, e (iii) as experimentações da utilização de computadores na performance, em 1990.

Se o primeiro e o ultimo períodos foram inspirados pelo desenvolvimento de novas tecnologias, já a proliferação das performances multimédia no período intermédio está associada ao desenvolvimento da capacidade de utilização simultânea de diversos meios e, principalmente, a uma maior inspiração artística associada a diversas alterações ideológicas e culturais (Dixon, 2007).

Importa assim refletirmos sobre estas alterações, interligando e relacionando os artistas, as obras e os propósitos associados, de forma a perceber o desenvolvimento da performance multimédia neste período. 


\section{A Reconstrução Visual do Fenómeno Sonoro}

A partir dos anos 2000 defendemos que se dá uma nova expansão da performance multimédia com a aparição de novas abordagens e de novos projetos, assentes em três abordagens distintas: (i) o som desenvolvido em função do visual; (ii) o visual desenvolvido em função do som e (iii) o visual gerado algoritmicamente.

De forma a desconstruir estas abordagens propomo-nos interligar e justapor o trabalho e as obras dos artistas mais representativos destas abordagens. Estes trabalhos refletem as últimas abordagens associadas à reconstrução do fenómeno sonoro e influenciam igualmente $\mathrm{o}$ trabalho de investigaçãocriação que o autor tem vindo a desenvolver.

\section{A Articulação Sonora e Visual}

Para o desenvolvimento desta leitura pessoal partimos de obras, gravações e performances sonoras e visuais que desenvolvemos nos últimos anos, interligando e relacionando os conceitos e os propósitos, associados à música eletrónica ambiental e à performance, de forma a desenvolvermos uma proposta de criação pessoal na performance contemporânea, baseada numa articulação sonora e visual no aqui e agora, que parte de uma construção pessoal e de uma prática artística concreta.

Os trabalhos produzidos e compartilhados por diferentes territórios criativos, cruzam-se, implicam-se e sobrepõem-se com as ideias e coerência da ação, que é a do autor e artista.

Estes trabalhos representam ainda vários espaço-tempo onde foi alcançado um grande grau de performatividade entre espaço, espectador e artista, envolvendo quer a exibição de competências técnicas, quer padrões de comportamento culturalmente codificado.

\section{Um Trajeto Artístico e Pessoal}

Neste trajeto artístico pessoal partimos de dois trabalhos iniciais do autor para convocar paisagens sonoras atmosféricas intimistas e contemplativas. Fruto da necessidade de apresentar ambos os trabalhos ao vivo, foi pensada e desenvolvida uma áudio performance.

De forma a suprir alguns preconceitos sonoros, visuais e espaciais, tornou-se então necessário desenvolver uma nova proposta de criação ampla e disponível para negociar com maior grau de autonomia o presente preceptivo.

Este caminho assentou numa articulação sonora e visual, que teve em conta o diálogo entre a música eletrónica ambiental e a imagem no aqui e agora, para que o espectador tenha uma imersão contemplativa num ambiente percetual, que o transporte para lugares imaginários através da criação de novas narrativas.

A conceção destas novas narrativas parte da alteração da realidade momentânea através da manipulação de clips sonoros e visuais, clips estes que são preparados previamente e criados recorrendo a recolhas sonoras e visuais efetuadas em contexto local e a texturas sonoras e padrões visuais desenvolvidos especificamente para os locais de apresentação.

O sucesso destas novas narrativas depende também do adensar sonoro que o ambiente visual potencia, produzindo assim uma maior espessura imersiva que a simples captura direta da realidade não encerra.

Este adensar em profundidade, que procura uma nova articulação sonora e visual, reflete ainda a complementaridade do espaço e do tempo, que nos trabalhos anteriores não eram deliberadamente explorados na sua dimensão site-specific.

Esta abordagem pessoal da performance sonora e visual radica no conceito de performance e de performance multimédia, trazendo ainda à discussão o conceito de performatividade.

Os conceitos de performance e performatividade podem ser explicados através de diferentes entendimentos, que são resultantes de distintas abordagens disciplinares, áreas artísticas ou contextos culturais (Carlson, 2004).

Para o âmbito do presente trabalho assumimos que as noções de performatividade estão vinculadas à arte como uma rede de trocas entre ação artística e público, pautadas não apenas pelo sentido da representação, mas na aproximação entre a arte e a vida, e na diluição das fronteiras que as configuram.

Alguma falta de entendimento e coerência conceptual na consolidação dos conceitos de performance e performatividade acaba por potenciar a performance multimédia, nomeadamente na exploração de diferentes conceções, proporcionando assim uma leitura pessoal sobre a interligação entre o visual e o sonoro, no aqui e agora, como tema de exploração criativa.

Se tivermos atentos às suas mais comuns definições, multimédia e performance não são dois conceitos entre os quais se possa encontrar imediatamente uma relação. De forma geral, entendemos por multimédia a combinação de meios ou de tipos de média (Packer e Jordan, 2001). Já a performance define uma apresentação/execução física frente a uma audiência (Carlson, 2004).

Para o desenvolvimento do nosso trabalho seguimos o conceito de performance multimédia conforme proposto por Klich (2007) que o apresenta como sendo um espaço onde um performer pode não estar presente, mas onde é alcançado um alto grau de performatividade e energia, descentrando-se do corpo/performer e expandindo-se a outros media, nomeadamente o som e a imagem.

\section{Ontologia e Estética}

De forma a construir esta nova articulação sonora e visual importa discutir também a natureza, os princípios e a essência da performance sonora e visual. Isto implica encontrar novos contornos estéticos e novas contaminações, associadas à experiência da performance sonora e visual.

As evoluções tecnológicas e artísticas ao longo do tempo permitiram uma fusão entre várias artes 
permitindo aos artistas poderem jogar e desenvolver uma estética particular, cujos elementos fundamentais são o movimento, a luz e a música. Ao juntar imagens em movimento e som de forma síncrona a experiência estética tornou-se muito mais intensa.

Com efeito, ao criar uma sintonia entre meios, neste caso o som e a imagem, cria-se também uma sintonia entre sentidos e é a partir desta sintonia que a experiência pode criar um efeito imersivo.

Efeito este que o famoso compositor alemão do século XIX, Richard Wagner, tentou produzir no espetador através daquilo que denominou como Gesamtkunstwerk, ou seja, obra de arte total, conceito muito semelhante ao conceito de multimédia, tal como proposto por Packer e Jordan (2001).

A Gesamtkunstwerk é feita a partir da integração de várias artes, como a música, o teatro ou a dança. $E$, da mesma forma, a multimédia é composta por vários meios de informação, como o vídeo ou o som.

\section{Meios e Intermedialidade}

Tal como apresentado anteriormente, Paker e Jordan (2001) ao estudarem o fenómeno multimédia procuram definir este conceito como a reunião das seguintes características: integração, interatividade, hipermédia, imersão e narratividade.

A integração é como tudo começa ao combinar formas artísticas com tecnologia criando uma forma híbrida de expressão. A interatividade segundo estes autores diz respeito à habilidade de manipular e usar os meios para comunicar com terceiros. A hipermédia significa a capacidade de separar os elementos de cada meio de outros elementos, no sentido de uma associação pessoal. A imersão diz respeito à experiência de entrar numa simulação ou sugestão de um ambiente tridimensional. E por fim, a narratividade baseia-se na estética e estratégias formais que derivam dos conceitos anteriores, que resultam em narrativas não-lineares e apresentação através dos meios.

Os meios tecnológicos na expressão artística vão ao encontro da ideia de obra arte total de Wagner, já que permitem a integração de diferentes artes na mesma obra e é neste sentido que os novos média possibilitam assim o dialogo e comunicação entre realidades artísticas diferentes.

Ao mesmo tempo estes meios tecnológicos e multimédia são meios de reprodução auxiliares do objeto artístico, tornando-se eles próprios objetos artísticos, formas de arte distintas e autónomas ligadas apenas por laços de descendência das outras artes.

Nenhum outro fator influenciou as vanguardas artísticas como a tecnologia. Esta não só tem alimentado a imaginação dos artistas como penetrou até ao âmago do próprio trabalho artístico (Rutsky, 1999). Mas, e tal como enfatizado por Puttnam (1999), os meios tecnológicos e a multimédia devem ser vistos como uma ponte entre objetos artísticos e não como o destino artístico.

Intimamente associado aos meios está o conceito de intermedialidade que designa práticas comunicacionais desenvolvidas simultaneamente em, ou para, diferentes media, ou usando meios e dispositivos comuns a diferentes media (Mendes, 2011).

Esta deia é reforçada por Chapple e Kattenbelt (2006) quando defendem que intermedia é um espaço onde as fronteiras se suavizam e onde estamos entre e no meio de uma mistura de espaços, meios e realidades. Estes autores reforçam ainda que a intermedialidade se torna um processo de transformação de pensamentos e processos em que algo é formado através da performance. No fundo como uma re-perceção do todo, que é reconstruído através da performance.

A arte é um mecanismo de estímulo das emoções e sentidos e a multimédia, através dos media e da intermedialidade, é uma extensão destas mesmas emoções e sentidos no indivíduo, permitindo experienciar sensações que não estariam ao alcance de outra forma.

\section{A Áudio-visualidade}

O recurso a diferentes media restringe-se nesta proposta para a criação de performances intermédias site-specific à articulação sonora e visual como ativadora da performatividade da memória do público.

Memória esta que permite a criação atual de uma ausência, podendo afirmar-se então que toda a memória parece implicar um trabalho de representação.

Sendo que este trabalho de representação, tal como Ricoeur (2006) defende, também tem inerente um processo de recordação, que precede um processo de construção de sons e imagens. Sons que se imaginam ouvidos, imagens que se pensam já terem sido visualizadas e sons e imagens entendidos como auxiliares na experiência viva da construção da memória.

A este processo de representação é acrescentado um outro nível de leitura com a interferência do sentido do lugar já que, tal como argumenta D'Annunzio (1983), as experiências mais ricas [nos espaços] acontecem muito antes de a alma se perceber já que, quando começamos a abrir nossos olhos para o visível, já somos defensores do invisível há muito tempo.

Assim, podemos assumir a importância da atmosfera de um lugar que lhe confere o seu caráter e identidade preceptivos únicos, tal como corroborado Pallasmaa (2006).

Estas dimensões de leitura, de sons, de imagens e de lugar, podem ainda ser associadas à áudiovisualidade, tal como proposto por Chion (1994), enquanto lugar de imagens e de sons. Por um lado, o som mostra a imagem de forma diferente do que a imagem mostra sozinha e, por outro lado, a imagem faz ouvir o som de maneira diferente do que se o som estivesse a tocar no escuro, reforçando assim a importância da articulação sonora e visual enquanto ativador da performatividade da memória.

\section{Notas Conclusivas}

Tal como referido anteriormente os conceitos de performatividade e performance podem ser explicados através de diferentes entendimentos, que são resultantes de distintas abordagens disciplinares, 
áreas artísticas ou contextos culturais. É esta falta de coerência conceptual que promove o seu potencial, nomeadamente na exploração das diferentes conceções e de forma a proporcionar uma leitura pessoal sobre a ligação entre o visual e o sonoro como tema de exploração criativa.

Em vez de procurar estabilizar estes conceitos, procuramos apresentar uma deriva sobre as ideias principais de performance e performatividade. A abertura das performances multimédia a outros media, como o som, a luz e a imagem, promove a discussão e da importância das capacidades imersivas e narratividades desta nova articulação sonora e visual, à luz dos conceitos propostos por Packer e Jordan (2001), Schechner (2003), Carlson (2004), Klich (2007) e Dixon (2007).

Quando o som e a imagem captam dois sentidos ao mesmo tempo num único sentido estético-narrativo, dá-se uma articulação que para além de captar a atenção do espectador, direciona-o para novas interpretações, tal como defendido por Chion (1994), Chapple e Kattenbelt (2006) e Ricoeur (2006).

De forma a promover uma articulação entre som e imagem foi desenvolvido um conjunto de performances intermédia site-specific, inspiradas na memória e na identidade de contextos locais. Estas têm como ponto de partida a perceção e interação com os espaços, enfatizando o sentido de lugar (D'Annunzio, 1983; Pallasmaa, 2006).

Além da incorporação de gravações de campo e soundscapes, a articulação sonora e visual procura representar as características dos lugares, incluindo alguns dos seus aspetos sociais e identitários mais particulares.

Nestas performances o contexto local circunscreve a sua aura e memória e o público projeta as suas próprias emoções e produtos mentais da perceção sobre a criação, criando dinâmicas de performatividade e experiências relacionais com o público.

Trata-se assim de uma abordagem pessoal à performance intermédia site-specific que procura desenvolver uma componente relacional emotiva, que conduza o espectador à criação da sua própria narrativa e articulação sonora e visual.

\section{Bibliografia}

Buck, Joseph. 2008. Brian Eno - Ambient 1: Music For Airports. http://www.musthear.com/music/reviews/ brian-eno/ambient-1-music-for-airports. Acedido em 29 de janeiro de 2018

Cage, John. 1961. "The Future of Music: Credo \{1958\}". In Silence: Lectures and Writings. John Cage. Hanover: Wesleyan University Press.

Carlson, Marvin. 2004. "What is performance?". In The Performance Studies Reader. Henry Bial and Sara Brady (eds.). London and New York: Routledge.

Chapple, Freda and Chiel Kattenbelt. eds. 2006. Intermediality in Theatre and Performance. Amsterdam and New York: Rodopi.

Chilvers, Ian and John Glaves-Smith. 2009. A Dictionary of Modern and Contemporary Art. Oxford: Oxford University Press ( $2^{\mathrm{a}}$ ed.).
Chion, Michel. 1994. Audio-vision: Sound on screen. New York: Columbia University Press.

Cowell, Henry. 1996. New musical resources. Cambridge: Cambridge University Press.

Coyne, Richard. 1999. Technoromanticism: digital narrative, holism and the romance of the real. Cambridge and London: The MIT Press.

Gabriele d'Annunzio. 1983. "Contemplazioni della morte $\{1912\}$ ". As quoted in Water and Dreams: An Essay on the Imagination of Matter. Gaston Bachelard. Dallas: The Pegasus Foundation.

Dixon, Steve. 2007. Digital performance: a history of new media in theater, dance, performance art, and installation. Cambridge and London: The MIT Press.

Hegarty, Paul. 2007. Noise/Music: a history. London: Continuum International Publishing Group.

Kaprow, Allan. 1966. Assemblage, environments \& happenings. New York: H. N. Abrams.

Klich, Rosemary. 2007. Multimedia theatre in the virtual age. PhD Thesis. School of Media Film and Theatre University of New South Wales.

Manovich, Lev. 2002. The Language of New Media. Cambridge and London: The MIT Press.

Mendes, João Maria. 2011. Introdução às intermedialidades. Lisboa: Escola Superior de Teatro e Cinema/IPL.

Packer, Randall and Ken Jordan. Eds. 2001. Multimedia: from Wagner to virtual reality. New York: Norton \& Company.

Pallasmaa, Juhani. 2014. "Space, Place, and Atmosphere: Peripheral Perception in Existential Experience". In Architectural Atmospheres: On the Experience and Politics of Architecture. Christian Borch (ed.). Berlin: Birkhäuser.

Puttnam, David. 1999. Keynote speech, Comunicação apresentado na CADE 99 (Computers in Art and Design Education) Conference, 7 de abril 1999. Middlesbrough, University of Teesside.

Ricoeur, Paul. 2004. Memory, History, Forgetting. Chicago: The University of Chicago Press.

Russcol, Herbert. 1972. The liberation of sound: an introduction to electronic music. Englewood Cliffs, NJ: Prentice-Hall.

Russolo, Luigi. 1967. The Art of Noise: futurist manifesto. London: A Great Bear Pamphlet by Something Else Press.

Rutsky, RL. 1999. High techne: art and technology from the machine aesthetic to the posthuman. Minneapolis and London: University of Minnesota Press.

Schechner, Richard. 2003. Performance theory. New York: Routledge.

Wagner, Richard. 2001. "The artwork of the future \{1849\}". In Multimedia: from Wagner to virtual reality. Randall Packer and Ken Jordan (eds.). New York: Norton \& Company.

Wardrip-Fruin, Noah. 2006. Expressive processing: on process-intensive literature and digital media. PhD Thesis. Brown University, Providence, Rhode Island. 